\title{
Rho GTPases regulation of Cell Polarity and Growth in Yeasts
}

\author{
Pilar Perez* and Sergio A. Rincón \\ Instituto de Microbiología Bioquímica, Consejo Superior de Investigaciones Científicas \\ (CSIC) / Universidad de Salamanca. Edificio Departamental. 37007 Salamanca, Spain. \\ * Corresponding author \\ Telephone: $34-923-121644$ \\ FAX: 34-923-224876 \\ E-mail: piper@usal.es
}

Key words: Cdc42, GEF, GAP, cytoskeleton, cell integrity, morphogenesis,

\section{SUMMARY}

Eukaryotic cells display a wide range of morphologies important for cellular function and development. A particular cell shape is made via the generation of asymmetry in the organization of cytoskeletal elements, usually leading to actin localization at sites of growth. The Rho family of GTPases is present in all eukaryotic cells, from yeast to mammals, and their role as key regulators in the signaling pathways that control actin organization and morphogenetic processes is well known. In this review we will discuss the role of Rho GTPases as regulators of yeast's polarized growth, their mechanism of activation and signaling pathways in Saccharomyces cerevisiae and Schizosaccharomyces pombe. These two model yeasts have been very useful in the study of the molecular mechanisms responsible for cell polarity. As in other organisms with cell walls, yeast's polarized growth is closely related to cell wall biosynthesis, and Rho GTPases are critical modulators of this process. They provide the coordinated regulation of cell wall biosynthetic enzymes and actin organization, required to maintain cell integrity during vegetative growth.

\section{INTRODUCTION}

Cellular shape is consequence of cellular growth, which is, in many cases, highly asymmetric. Polarized cell growth is fundamental to morphogenesis and the development of both unicellular and multicellular organisms [1]. In general, cell polarization is a response to specific internal or external cues that generate cellular asymmetry. Understanding how molecular interactions and cellular components can generate asymmetry remains one of the fundamental problems in biology. Unicellular organisms, such as the budding yeast Saccharomyces cerevisiae and the fission yeast Schizosaccharomyces pombe, provide excellent models to study polarized growth because their morphology, size, and division habits are extremely reproducible. The advantages of simplicity, being unicellular organisms, and straightforward genetics, make yeasts potent systems for addressing important questions in cell morphogenesis.

Polarized growth requires a perfect coordination among major cellular processes such as cytoskeletal organization, secretion, and endocytosis that have to be controlled by the cell integrity pathway and regulated by the cell cycle. First of all, cells need to select growth sites and then reorganize their cytoskeleton and growth machinery 
accordingly [2]. The major players involved in the establishment of sites for polarized growth, such as the Rho GTPases or PAK proteins, are conserved from yeast to mammals, suggesting that the basic mechanisms involved may be conserved throughout evolution. S. cerevisiae has six Rho GTPases, named Rho1-5 and Cdc42 [3]. S. pombe also has six genes coding for Rho GTPases, $r h o 1^{+}$to $r h o 5^{+}$and $c d c 42^{+}$. In both yeasts only Rho1 and Cdc42 are essential $[4,5]$.

\section{RHO GTPases}

Rho proteins belong to the Ras superfamily of small $\mathrm{G}$ proteins highly conserved in all eukaryotic organisms. They are GTP-binding proteins with biochemical similarity to heterotrimeric $\mathrm{G}$ proteins $\alpha$ subunit, whose molecular conformation changes depend on the nucleotide they are bound to [6]. They are active only when they are bound to GTP and can interact with effector proteins. Meanwhile, when they are bound to GDP, they cannot interact with their targets, so the signal is no longer transmitted. That is why they are known as "molecular switches" [7]. However, Rho proteins do not necessarily need to undergo switching. For example, the ability of Rhol to activate the enzyme glucan synthase does not require GTP hydrolysis [8].

Rho GTPases display a high affinity for both GDP and GTP. However, only when they are bound to GTP are their switch regions exposed, allowing them to interact with a variety of target proteins to carry out their molecular functions [9]. On the other hand, Rho proteins have an intrinsic GTPase activity; therefore, they can hydrolize GTP to GDP, which leads to a change in the conformation and inactivation of the protein. The transition from GDP- to GTP-bound Rho proteins is controlled by GEFs (Guanine nucleotide Exchange Factors) that interact with Rho proteins and alter the nucleotide binding site, thus facilitating the release of the nucleotide [10] (Figure 1). Since the cytoplasmic concentration of GTP is higher than that of GDP, it is more likely that the GTPase binds to GTP than to GDP. Alternatively, GAPs (GTPase Activating Proteins) promote the hydrolysis of GTP bound to Rho proteins by correctly orienting the $\mathrm{H}_{2} \mathrm{O}$ molecule necessary for the hydrolysis and by stabilizing the transient state of the reaction [10]. The number of RhoGEFs and RhoGAPs overcomes that of Rho proteins [10]. A single Rho GTPase is regulated by more than one RhoGEF or RhoGAP [11]. At the same time, it has been shown that RhoGEFs and RhoGAPs regulate more than one Rho protein. This promiscuity led to the hypothesis that a Rho protein might be regulated by different RhoGEFs and RhoGAPs for specific processes. For instance, $S$. pombe Cdc42 has two GEFs, Scd1 and Gef1, the first mainly regulating apical growth and the latter mainly regulating cytokinesis [12] [13]. RhoGEFs and RhoGAPs are multidomain proteins with the ability to bind to other proteins or to membranes. This enables them not only to change the activation state of the Rho GTPase, but also to serve as scaffold proteins in order to couple the upstream signal with downstream effectors and to directly localize the Rho GTPase [10].

Rho proteins are also regulated by RhoGDIs (Guanine Nucleotide Dissociation Inhibitor). These proteins act as negative regulators of Rho GTPases at three levels: inhibiting the dissociation of GDP from Rho proteins; blocking intrinsic and GAPstimulated GTPase activity; and extracting Rho GTPases from membranes by masking their isoprenoid group, thus preventing their activation by RhoGEFs [14](Figure 1).

\section{RHO PROTEINS IN YEAST POLARIZED GROWTH}


Understanding how cellular components can generate asymmetry and establish polarized growth is essential for the understanding of morphogenesis. External or internal spatial cues determine the selection of the specific site where the growth machinery will be activated. During vegetative growth, the cell uses internal cues to activate growth in a coordinated fashion with the cell cycle progression [15]. The two model yeasts, $S$. cerevisiae and $S$. pombe, have very different cell growth patterns and molecular pathways linking growth site selection and growth activation, as will be described below.

Polarized growth can be divided in three key steps: 1) Marking of the polarization site in response to internal or external signals to the cell. 2) Establishment of polarity by recognition of the polarization site and signaling to the cytoskeleton to allow its asymmetric organization. 3) Asymmetric distribution of the cellular components and polarized secretion, leading to polarized cell growth. Rho GTPases are activated specifically in the vicinity of the "landmark proteins" that mark the site and are required in the establishment of polarity and in the polarized growth.

\section{Establishment of Polarized Growth: the master regulator Cdc42}

a) S. cerevisiae cells have a slightly elongated round shape and divide by the formation of a single bud per cell cycle, which grows in an apical manner in early G1 to get a critical size. Then, the bud growth shifts to isotropic and the bud becomes round. After mitosis, when the nuclei have separated, a septum is formed between mother and daughter cells, physically separating them. This septum is eventually degraded, allowing the release of both cells. The budding site is selected according to the positional information of the former budding cycle. In haploid cells, buds are assembled adjacent to the place where the former bud emerged (axial pattern). In contrast, in diploid cells buds are formed at the distal pole where the last bud was made (bipolar pattern). The GTPase Bud1/Rsr1, its GEF, Bud5, and its GAP, Bud2, are the core elements connecting the cortical cues to Cdc42 [16].

The key step in the establishment of polarized growth is the accumulation of active $\mathrm{Cdc} 42$ to the presumptive bud site. Cdc 24 is the only GEF controlling Cdc42 activity and cell polarization [15]. Loss-of-function $c d c 24$ mutant strains display a phenotype similar to $c d c 42$ mutants. Cdc24 PH (Pleckstrin Homology) domain, which binds phosphoinositides, and Cdc24 interaction with several proteins are necessary for a tight localization of this GEF to the bud site [16]. During early G1 phase Cdc24 remains sequestered by the protein Far1 in the nucleus, avoiding ectopic activation of Cdc42. G1 cyclin-Cdc28 phosphorylation of Far1 in late G1 triggers its degradation and the release of $\mathrm{Cdc} 24$ from the nucleus $[17,18]$. G1 cyclin-Cdc28 phosphorylates $\mathrm{Cdc} 24$ in vitro. However, the relevance of such phosphorylation is controversial; while some authors have found that a point mutation in a consensus G1 cyclin-Cdc28 phosphorylation site results in Cdc24 localization defects [19], others have not detected such defects in Cdc24 with all consensus phosphorylation sites mutated, concluding that phosphorylation may not be a major regulation process for Cdc24 [20]. G1 cyclinCdc28 might be required for phosphorylating other Cdc24 complex proteins such as Rga2, Boil or Boi2 [21]. Cdc24 localization is also regulated by oligomerization. Induction of $\mathrm{Cdc} 24$ oligomerization results in reduction of active $\mathrm{Cdc} 42$ due to a delay in $\mathrm{Cdc} 24$ nuclear export [22].

Bud1/Rsr1 interaction with Cdc24 triggers the correct localization of this GEF to the selected site (Figure 2A). This results in a local activation of Cdc42, which dictates the polymerization of the actin cytoskeleton and targets secretion to the selected bud 
site. Even in the absence of a functional Bud1/Rsr1 module, Cdc24 and active Cdc42 are able to cluster at a single cortical site in a random fashion. This suggests that Cdc24 accumulation may be controlled by a parallel pathway. One possibility is that Bem1, a scaffold protein able to bind $\mathrm{Cdc} 24, \mathrm{Cdc} 42$, and the kinase Cla4, facilitates the interaction of $\mathrm{Cdc} 42$ with other proteins, allowing its cortical clustering. The double mutant bud14bem1 $1 \Delta$ is not able to activate bud emergence and it does not show polarized $\mathrm{Cdc} 42$. It has recently been shown that the expression of the fusion protein Cdc24-Cla4 can bypass the requirement for Bem1 in the absence of Rsr1 [23]. This observation led to the hypothesis that the role of Bem1 is to link Cdc24 and Cla4, and the interaction of $\mathrm{Cdc} 24$ and $\mathrm{Cla} 4$ is sufficient for "symmetry breaking" and polarization. This interaction would lead to a positive feedback loop in which Cla4 phosphorylates and activates $\mathrm{Cdc} 24$, which would activate $\mathrm{Cdc} 42$, which would activate Cla4 and thus amplify the signal pathway [24]. By contrast, other authors believe that Cdc24 phosphorylation by Cla4 leads to the dissociation of Cdc24 and Bem1 and thereby serves as a negative feedback loop that might help shifting from the apical to the isotropic growth [25]. However, the mutation of all Cdc24 phosphorylation sites leads to no apparent vegetative growth defects, raising the possibility that this Cla4 phosphorylation is not a major manner of Cdc24 regulation [20].

The initial clustering of $\mathrm{Cdc} 42$ to the presumptive bud site is independent of the actin cytoskeleton but F-actin influences $\mathrm{Cdc} 42$ dynamic distribution through its effects on two antagonic processes: targeted secretion and endocytosis [26]. Although Cdc42 clustering may initiate at more than one site, it has recently been shown that rapid competition between foci determines the winning focus, giving rise to the growth of a single bud [27]. In this focus, the distribution of Cdc42 is stably maintained by two mechanisms of dynamic recycling that are coupled to the GTPase cycle: Cdc42 GDI, Rdi1, mediates a fast recycling pathway, while endocytosis mediates a slower one [28].

S. cerevisiae has four Cdc42 GAPs: Rga1, Rga2, and Bem3 are Cdc42-specific GAPs, and Bem2 is also a GAP for Rho1 (Table I). The strain lacking Bem2 is thermosensitve, with large round cells, either unbudded or with a small bud, when grown at restrictive temperature. Surprisingly, this resembles a Cdc42 loss-of-function phenotype, not expected from the deletion of a Cdc42 GAP. Inactivation of Bem2 results in Cdc42 polarization toward multiple sites; therefore, Bem 2 might contribute to the restriction of Cdc42 activation at a single cortical site [29]. bem3A cells show an aberrant morphology, which is aggravated by the lack of $R G A 1$ and $R G A 2$, suggesting that these GAPs have a secondary role in polarized growth regulation. Additionally, the strain lacking $B E M 3, R G A 1$, and $R G A 2$ has a defect in septin ring assembly [30], which suggests a role of $\mathrm{Cdc} 42$ in the regulation of septin organization. Although these Cdc42 GAPs show somewhat overlapping functions, it is likely that their different localization pattern may account for differential regulation of $\mathrm{Cdc} 42$ at specific processes. Rga2, Bem2, and Bem3 are phosphorylated by G1 cyclin-Cdc28 during bud emergence and this phosphorylation reduces their GAP activity [21, 29, 31].

$S$. cerevisiae has one GDI, Rdi1, which can extract Cdc42 from internal and plasma membranes. Rdil localizes to the cytoplasm, to the tip of small buds and to the mother-bud neck region [16]. Although the lack of RDII does not affect vegetative cell growth in yeasts, diploid rdi1/ cells display a defect in filamentous growth [32]. It has been shown that overexpression of the Cdc42 effector protein Cla4 abolishes the interaction of Rdil and Cdc42 by an unknown mechanism [32]. Thus Cla4 would participate in a positive feedback loop disrupting the negative regulation of Rdil over Cdc42. 
Once $\mathrm{Cdc} 42$ is polarized to the presumptive bud site, it organizes the actin cytoskeleton, the septins, and the polarized secretion to carry out the polarized cell growth. To control all these processes, Cdc42 interacts with a variety of effector proteins such as: the PAKs (p21-activated kinases), Ste20, Cla4, and Skm1; the formin Bni1; the Gic proteins Gic1 and Gic2; and the exocyst subunit Sec3 (Figure 3).

PAKs are serine-threonine kinases that participate in a variety of cellular processes. Cdc42 interact with the CRIB domain of Ste20, relieving the intramolecular interaction responsible for its autoinhibited state [33]. Cdc42 also regulates the localization of Ste20 to the growing regions $[34,35]$. Ste20 deletion leads to a defect in pseudohyphal differentiation and mating response [35].

The other major PAK family member is Cla4. Deletion of Cla4 CRIB domain results in increased kinase activity, suggesting that the CRIB domain downregulates Cla4 kinase activity [36]. Deletion of both STE20 and CLA4 is lethal and the double mutant displays a phenotype of large unbudded cells similar to that seen in the $c d c 42-1$ mutant strain. Ste20 and Cla4 might regulate the conserved Arp2/3 complex that nucleates actin to form patches, highly dynamic actin structures involved in endocytosis [2]. Ste 20 and Cla4 phosphorylate and activate type I myosins Myo3 and Myo5, known Arp2/3 activators [37] [38] [39]. However, Cdc42 might not play an essential role in actin patch assembly, but rather in actin patch polarization since $c d c 42$ thermosensitive mutant strains display a depolarized pattern of actin patches throughout the cell cortex.

In $S$. cerevisiae, there are two formins, Bnil and Bnr1, which nucleate actin cables. Bnil localizes to the site of bud emergence at the cortex of larger buds, and then redistributes to the mother-bud neck during septum formation. Bnrl localizes to the mother-bud neck after bud emergence and remains until cytokinesis. Bnil nucleates actin cables from the bud tip, while Bnrl assembles actin cables towards the bud neck [2]. Cells lacking Bnil and Bnr1 are not viable. Besides their differential localization and physiological functions, they seem to have different dynamics and mechanics for anchoring to the cell cortex [40]. Bnil interacts in a two-hybrid assay with Rho1, Rho3, and Cdc42, while Bnr1 specifically interacts with Rho4 [41]. Rho3 and Rho4 seem to be the main activators of formin activity [41]. S. cerevisiae Cdc42 seems to have a main role in polarizing actin cables and a secondary role activating formins in the absence of both Rho3 and Rho4. Cdc42 effect in the actin cables organization is probably due to its role in the localization of Bni1. However, depolarized formin activity can still produce a partially polarized actin cytoskeleton, in a mechanism dependent on the type II myosin Myo1 [42]. This suggests that Cdc42 might have additional effects on actin cable polarization beyond Bnil localization. It is noteworthy that $\mathrm{Cdc} 42$ regulates Bni1 localization, which is in turn necessary for cortical targeting of the Arp $2 / 3$ activator Bee1 [39]. Therefore, Cdc42 regulates Arp2/3 activation not only through PAKs, but also through Bni1.

Cdc42 effectors Gic1 and Gic2 were discovered by sequence comparison looking for proteins that contained a CRIB domain [43]. Gic1 and Gic2 localize to the presumptive bud site, to the tip of the buds, to the mother-bud neck region, and to the tip of the mating projection [43] [44]. They require the interaction with $\mathrm{PIP}_{2}$ to properly localize to the bud tip, but not for plasma membrane association [45]. Gic proteins have a role in septin recruitment to the bud site since the double mutant gicl 1 gic $2 \Delta$ shows no septin localization at $37^{\circ} \mathrm{C}$ [46]. This result indicates that another pathway might be functioning at lower temperatures. The kinase Cla4 also plays a role in septin organization since cla4 4 cells display a defect in septin ring assembly and later septin reorganization [47-49]. Cdc42 GAPs also play a role in septin organization that might be related to the elongated bud phenotype of these cells [30] [46]. 
Another target of Cdc42 is the exocyst subunit Sec3 [50]. The characterization of $S$. cerevisiae cdc42-6 thermosentive strain that accumulated post-Golgi vesicles in small budded cells with no apparent actin defects, led to the hypothesis that $\mathrm{Cdc} 42$ regulates exocytosis independently of actin cable organization [51, 52]. Cdc42, together with $\mathrm{PIP}_{2}$ regulates Sec3 localization to the bud tip [50] [53]. Rho1 also has a role in the localization of Sec3 [54]. This protein and Exo70 are the only exocyst subunits present at the cell cortex and not in the secretory vesicles, and they might act redundantly as a spatial landmark indicating where the exocyst complex should be assembled to permit the vesicle tethering [55]. However, the secretion defect seen in $c d c 42-6$ cells is not a problem of exocyst localization, therefore $\mathrm{Cdc} 42$ might have additional roles in activating polarized secretion [52]. The mutant $c d c 42-6$ is suppressed by increased dosage of $\mathrm{RHO} 3$, concordant with a role of Rho3 in exocytosis. Rho3 positively regulates late secretory function through physical interaction with the Exo70 component of the exocyst [56]. Interestingly, disruption of the interaction between Rho3 and Exo70 did not cause a phenotype [55]. This suggests that Rho3 has additional roles in secretion. All these data led to the proposal of the "localized activation" model, in which activated $\mathrm{Cdc} 42$ and Rho3 bind to a cortical exocyst subunit triggering a conformational change in the exocyst complex that results in the relief of its autoinhibitory state [57]. The increase in the exocyst function would result in the deposition of more polarity factors, including $\mathrm{Cdc} 42$ and the components of exocyst complex, eventually amplifying the signal [58].

b) $S$. pombe cells are rod-shaped; they grow through tip extension and divide by the formation of a medial septum. These morphogenetic events are tightly coupled to cell cycle progression. Thus, during G1, cells grow through the old end in a monopolar manner. At the beginning of G2, when cells reach a critical size, growth is activated in the new end in a process known as NETO (New End Take Off) producing bipolar growing cells [59]. When cells enter mitosis, tip growth stops and upon nuclear division, an actomyosin ring forms and then contracts. Concomitantly, new membrane and cell wall material is deposited in an ordered fashion to separate the daughter cells. The controlled digestion of the primary septum will lead to the realease of the daughter cells, which will begin growing through their old ends.

Contrary to budding yeast, $S$. pombe microtubule (MT) cytoskeleton plays a crucial role in defining the site of polarized growth [60] [61]. The use of microfluidics techniques to change the normal shape of fission yeast cells and make them grow in a bent fashion has allowed confirmation that the sites of microtubule contact in the cell cortex accumulate polarity proteins and eventually give rise to an ectopic growing tip [62] [63]. Teal was the first discovered protein important for growth site selection. The lack of Teal leads to monopolar growing cells and to the activation of ectopic growth sites, especially in cells re-entering logarithmic growth [64]. Teal is transported in the plus end MTs and anchored to the cortex through the interaction with the membraneassociated protein Mod5 [65](Figure 2B). MT-transported Tea4 and Tea3 also play a role in Tea1 tethering to the cell tips, the first to the growing end and the latter to the non-growing end [66] [67]. Tea4 is an important link between Tea1 and For3, the formin required for actin cable assembly during interphase [68] [67].

The establishment of polarized actin cables relies on the Cdc42 activation of the interphase formin For3 [69]. For3 localizes to the growing ends and the division region through a complex regulation that involves $\mathrm{N}$-terminal and C-terminal domains [69]. It depends on two major proteins: the GTPase Cdc42 and Bud6 [69, 70]. The latter requires Teal for tip localization and, subsequently, contributes to For3 localization by 
anchoring its C-terminal region to the cell cortex [70] [69]. In the absence of Bud6, For3 is partially delocalized and cells display a less robust pattern of actin cable array [69]. Cdc42 relieves the autoinhibited state of For3 [69]. Moreover, cdc42 mutants show a severe defect in actin cables and For3 localization [69] [71]. These defects are partially suppressed by the expression of the Boi family member Pob1 [71]. The interaction of Pob1 with For3 is necessary for tethering For3 N-terminal domain and for Cdc42-mediated For3 activation [71]. Surprisingly, cells lacking For3 are viable despite the lack of detectable actin cables. It is possible that other molecules, such as the exocyst complex regulate polarized secretion and growth in the absence of actin cables.

$S$. pombe Cdc42 localizes to the growing ends, the division site and the endomembranes [72]. The lack of Cdc42 activity leads to small dense round cells, suggesting that although macromolecular synthesis continues, incorporation of new material to the membranes is inhibited [4]. These cells are also unable to mate [4]. There are two specific Cdc42 GEFs in S. pombe, Scd1 [73] and Gef1 [13] [12] (Figure $3)$. The double deletion of these genes is not viable, suggesting that Scd1 and Gef1 share the essential role of $\mathrm{Cdc} 42$ activation. Scd1 localizes to the nucleus, the mitotic spindle, the growing cell ends, and the septum [74], which suggests a variety of functions in different processes.

$S$. pombe establishment of cell polarity strongly differs from the budding yeast model in which Bud1/Rsr1 connects the landmark signal to Cdc42. S. pombe contains a Bud1/Rsr1 orthologue, called Ras1, which has been shown to play an important role both in mating and in vegetative polarized growth $[75,76]$. In contrast to $S$. cerevisiae, lack of Ras 1 activity leads to a polarized growth defect rather than to a defect in the selection of the polarized growth site, and cells become round. Nevertheless, the Ras1Cdc42 activation module is conserved in both yeasts. Thus, Scd1, the fission yeast Cdc42 GEF homolog to Cdc24, is a major Ras1 target [73]. Cells lacking Scd1 show a spherical phenotype, are incapable of mating [73], and have defective endocytosis [77]. Scd1 also plays a role in proper mitotic spindle formation [74]. Moreover, Scd1 together with $\mathrm{Cdc} 42$ have been shown to interact with the presumptive kinesins Klp5 and Klp6 to regulate cell separation [78]. However the mechanism of this regulation remains to be clarified.

The homolog protein of $S$. cerevisiae Bem1 in $S$. pombe is Scd2, a scaffold protein that stimulates Scd1 interaction with Ras1 and Cdc42 [73]. Scd2 binds to GTP-Cdc42 and facilitates its interaction with the downstream effector Shk1 [79].

Gef1, the other Cdc42 GEF, localizes to the cell equator during actomyosin ring contraction, and to the growing cell poles. Gefl deletion leads to a delay in cytokinesis and defects in NETO transition [13] [12]. It has recently been described that activated Cdc42 localization is regulated by the NDR kinase Orb6 through the proper localization of Gef1 to the poles. Defects in Orb6 signaling lead to Gef1 mislocalization to the cell sides, thereby ectopically activating Cdc42 [80].

The only Cdc42 GAP described in $S$. pombe is Rga4 [81]. This GAP localizes to the cell sides and to the division site, and is excluded from the cell tips [82] [81]. Rga4 was found as an interacting partner of the DYRK kinase Pom1 [81]. This kinase is localized to both cells ends and is required for NETO and actomyosin ring positioning [83]. Pom1 regulates Rga4 localization and therefore Cdc42 activation [81]. Cells lacking Rga4 are shorter and wider than wild type cells [82].

As in budding yeast, PAKs (Shk1 and Shk2) are Cdc42 effectors in S. pombe. Shk1 was identified in a screening for $S$. cerevisiae Ste20 homologs [84] [85]. Shk1 is essential, and the null mutant gives rise to round small cells reminiscent of the $c d c 42$ null cells. The expression of Ste20 suppresses the lethality of shk1 deletion, suggesting 
that the cellular functions of these proteins are highly conserved. It has been shown that Shk1 phosphorylates Tea1 in vitro and that both proteins might cooperate for proper cell division [86]. Moreover, it has been demonstrated that Shk1 has a negative effect on cytokinesis completion by phosphorylating myosin light chain [87]. The PAK Shk2 is not essential and cells lacking Shk2 do not show an apparent phenotype [88] [89]. Shk2 interacts with Cdc42 and when overexpressed can suppress the lethality of shk1 deletion [88, 89]. Shk2 has been shown to interact with Mkh1, the MAPKKK of the cell integrity pathway. Moreover, whereas Shk2 overexpression is lethal in a wild type background, it is not in cells lacking Mkh1 or the MAPK Pmk1 [90]. However, Shk2 does not seem to play a relevant role in the activation of that MAPK pathway [91].

Although there is a conserved Arp2/3 complex in $S$. pombe, so far it has not been reported to be regulated by Rho GTPases. $c d c 42$ conditional mutants at restrictive temperature [69] [71] or cells lacking Rho3 at high temperature [92] show delocalized actin patches, but it is not known whether this reflects the regulation of Arp2/3 by these proteins. Switching off $\mathrm{rhol}^{+}$expression causes disappearance of the actin cytoskeleton [93], suggesting a main role of this protein in maintaining actin polymerization. However the signaling molecules that participate in this process are not known.

Not much is known about polarized secretion in $S$. pombe. $r h o 3^{+}$gene was identified as a multicopy suppressor of $\sec 8-1$, a temperature-sensitive exocyst mutant [94]. rho3 also shows genetic interaction with exo70. Vesicles accumulate in rho3 $\Delta$ cells growing at $36^{\circ} \mathrm{C}$ and secretion is impaired [94]. Interestingly, rho $3^{+}$is essential only at higher temperature, whereas the exocyst complex is essential at all temperatures [95]. Rho3 function might be redundant with other proteins such as Cdc42. Indeed, the thermosensitivity of $c d c 42-879$ strain [71], which displays secretion defects, can be partially suppressed by increased dosage of $r h o 3^{+}$(our unpublished results). $S$. pombe Rho4 also regulates secretion in a non-redundant manner with Rho3 [96]. This GTPase is involved in secretion only during fission yeast cytokinesis [97], and it might be required for the exocyst localization at the division area (our unpublished results).

\section{RHO GTPases AND CELL INTEGRITY}

Polarized growth requires remodeling of the cell wall at the growing site. Growth in yeast is always limited by the existing cell wall. The cells must organize regions where the wall will be weakened to allow the incorporation of new material [8]. Therefore, a coordinated regulation of cell wall biosynthetic enzymes and actin organization is necessary to keep cell viability. Rho GTPases might be the key molecules in this coordination. The main structural component responsible for the rigidity and strength of the cell wall is the linear polymer 1-3- $\beta$-D-glucan. Direct activation by Rhol of the enzymes responsible for the biosynthesis of this polymer is a general mechanism in fungal wall biosynthesis $[3,8]$.

$S$. cerevisiae Rhol is an essential protein that localizes to the area of polarized growth independently of the actin cytoskeleton [98]. Rhol is activated by the GEFs Rom1, Rom2, and Tus1 [99, 100]. Rom1 and Rom2 have redundant functions in the activation of Rho1, and probably Rho2. Cells lacking both GEFs are not viable. Tus1 is also necessary for the cell wall integrity pathway [100] and its phosphorylation by Cln2Cdc28 is required for the efficient activation of Rho1 at the G1/S transition [101]. Tus 1 and Rom2 participate in Rho1 localization and activation during cytokinesis [102, 103]. The regulation of both GEFs is mediated by Polo kinase phosphorylation. 
Rho1 GDP/GTP cycle is regulated by the GAPs: Bem2, Sac7, Bag7, and Lrg1 [104] (Table 1). Bem2 and Sac7 negatively regulate the MAPK cell integrity pathway $[105,106$ 245]. Sac7 and Bag7 have some redundant functions in the Rho1 regulation of actin organization [106]. Lrg1 is the main regulator of Rho1 as activator of the $\beta$ $(1,3)$ glucan [107]. The compensatory effect of GEFs and GAPs in Rhol activity regulation is known, because a $S$. cerevisiae strain lacking all the GEFs is viable in the absence of the GAPs Lrg1 and Sac7 [103]. GTP-bound Rho1 interacts with six effector proteins: $(1,3) \beta$-glucan synthase components, Fks1 and Fks2, Pkc1, the formin Bni1, the Skn7 transcription factor, and the Sec3 exocyst subunit [3] (Figure 4).

S. pombe Rho1 has $73 \%$ and $67 \%$ identity with $S$. cerevisiae Rhol and Homo sapiens RhoA respectively [108]. Rhol localizes to places of active cell growth [93]. and plays an essential role in cell wall biosynthesis and actin cytoskeleton regulation [5, 109]. This GTPase is activated by three GEFs called Rgf1, Rgf2, and Rgf3 [110-113]. All of these GEFs have similar molecular structures to the budding yeast Rho1-GEFs Rom1 and Rom2 [113]. Rgf1 specifically regulates Rho1 during polarized growth [113] and Rgf3 during cytokinesis [110]. Rgf2 performs an essential function during the sporulation process and a secondary function redundant to Rgfl during polarized growth [114].

Rho1 is negatively regulated by three GAPs, Rga1, Rga5, and Rga8 [115-117] and, likely, by the GDI Rdil, which also binds Rho4 and Cdc42 [118]. Rga1 is a major regulator of Rhol and cells lacking Rgal are sick and have a thick cell wall [115]. Rga5 regulates cell integrity and cytokinesis [116]. Rga8 is a Rho1 GAP regulated by Shk1, therefore it might participate in the crosstalk between Rho1 and Cdc42 [117].

$S$. pombe $r h o 2^{+}$was isolated in a screening of genes causing aberrant morphology when overexpressed. $r h o 2^{+}$overexpression causes actin depolarization, and an increase in the amount of cell wall $\alpha$-glucan. [119, 120]. Like Rho1, Rho2 localizes to the growth areas [119] and interacts with Pck1 and Pck2 [121]. However, only Pck2 seems to be part of the Rho2 signaling [120]. rho $2^{+}$is not essential but cells lacking Rho2 have some cell wall defects $[119,120]$. No GEF-activating Rho2 has been described. The GAP Rga2, structurally similar to S. cerevisiae Bem3, is a specific Rho2 GAP that also participates in the regulation of cell dimensions, probably through the interaction with Cdc42 [122].

\section{The PKC-MAPK Cell Integrity Pathway}

Rho1 is a direct activator of the $(1,3) \beta$-D-glucan synthase, which is the enzyme responsible for the synthesis of the main cell wall polymer in both budding and fission yeast. Additionally, in $S$. cerevisiae it also activates the kinase from the PKC family that triggers the MAPK cell integrity pathway. Any cell wall defect is detected by a family of membrane receptors, Wsc1-4, and Mid2-Mlt1 [3] (Figure 4). MID2, MTL1, and the WSC genes show distinct expression patterns, indicating that these sensors mediate signaling under different conditions [123]. Wsc1 and Mid2 act during cell wall remodeling required for vegetative growth. Additionally, Mid2 acts during the mating process to ensure cell wall integrity during projection formation. Wsc1 and Mid2 interact and activate Rho1 through the GEF Rom2 [124]. Although Rom1 and Tus1 are also Rho1-GEFs, the upstream signaling is not clear. Interestingly, Tor2, an essential phosphatidylinositol kinase involved in the coordination between nutritional signals and cell growth, also regulates actin organization by activating Rom 2 and Pck1 [3, 125, 126]. Thus, Tor 2 might act as a nutrient sensor that connects protein synthesis, required for active growth, with cell wall biosynthesis and cell integrity. It has been 
demonstrated recently that the Pkc1 pathway is required for viability in quiescence acting downstream of TOR to maintain cell integrity [127].

Yeast PKCs are structurally and functionally related to the Rho-associated kinases (PRKs) of mammalian cells. They contain Rho1-binding domains that are responsible for their stabilization and targeting to the bud tip [121, 128]. The binding of GTP-RhoA leads to a conformational change in PRKs that allows PDK1 binding and phosphorylation of the PRK activation loop [129]. A similar mechanism may cause yeasts PKCs activation. S. cerevisiae has two homologs of PDK1, Pkh1 and Pkh2, which share an essential function as activators of Pkc1 [130]. Pkc1 is localized and stabilized by active Rho1 to the growth areas where it is activated by Pkh1 or Pkh2 and triggers the MAPK cell integrity pathway. This pathway activates the transcription factor Rlm1, which regulates the expression of at least 25 genes related to cell wall biosynthetic processes, including (1,3) $\beta$-glucan synthase coding genes $F K S 1$ and $F K S 2$ [3]. Interestingly, the function of the MAPK pathway is only indispensable in conditions of high temperature $\left(37^{\circ} \mathrm{C}\right)$, since the mutants lacking this route lyse at high temperature. Both Rhol and Pkc1 have additional effects in the control of integrity, since $p k c 1$ mutants require osmotic stabilization at all temperatures and rhol mutants lysis occurs even in presence of osmotic stabilizer [3].

In $S$. pombe, the signaling mechanism from the cell surface to the Rho GTPases is not known. Proteins similar to the Wsc family of receptors exist but their relationship with Rho proteins is not clear. GTP-bound Rho1 and Rho2 interact with the two fission yeast PKC homologs Pck1 and Pck2 [121, 122]. Both bind to Rho1 and Rho2 [121] (Figure 4). Pck1 and Pck2 are unstable and the interaction with GTP-Rho1 or GTPRho2 increases their stability $[121,122]$. S. pombe Ksg1 kinase is homolog to human PDK1 [131]. It is possible that this kinase activates Pck1 and Pck2 although it has not been studied. $p c k 1^{+}$and $p c k 2^{+}$share overlapping roles in cell viability but only Pck2 is able to activate the integrity pathway downstream of Rho2 [132], while Pck1 has a negative effect [133]. The role of Rho1 in the integrity pathway is not clear. It has been recently described that the Rho1 GEF Rgfl activates this pathway [114].

$S$. pombe MAPK integrity module includes Mkh1 (MAPKKK), Pek1/Shk1 (MAPKK), and Pmk1/Spm1 (MAPK)[134-138] (Figure 4). Deletion of any gene in this module causes cytokinesis defects, hypersensitivity to potassium ions and $\beta$-glucanase treatment, and vacuole fusion defects [134, 136-139]. It has been described that under cell wall damage conditions Pmk1 can phosphorylate the transcription factor Atfl [140], which is phosphorylated also by Sty1 [141]. These authors propose that the cell integrity and stress pathways converge in Atfl in order to activate genes required to repair cell damages [140]. However, no activation of any gene related to cell wall biosynthesis has been proved yet.

\section{RHO PROTEINS IN CYTOKINESIS}

Cytokinesis is required for the separation of daughter cells after mitosis. Animal and fungal cells organize an actomyosin contractile ring necessary for cell cleavage [142]. Besides actin and myosin, which form intercrossed filaments, at least 20 other proteins are required to form the ring, most of them conserved among eukaryotes. (See reviews [143-145]). In yeast cells, ring constriction and septum formation are coordinated and several regulatory proteins form a signaling pathway, named MEN (Mitosis Exit Network) in S. cerevisiae and SIN ( Septation Initiation Network) in $S$. pombe. These pathways trigger the contraction of the F-actin ring and coordinate cytokinesis with the nuclear cycle (see reviews [114, 145-147]). 
In animal cells RhoA is essential in the assembly and contraction of the CAR (Contractile Actomyosin Ring). Similarly, in budding yeast Rhol is required for Bni/Bnr1 assembly of the actomyosin ring [148]. Rho1 is localized and activated at the division area by Tus1 and Rom2 during CAR assembly [102] and the regulation of both GEFs is mediated by Polo kinase phosphorylation. Rho1 is also localized later by interaction with the membrane micro domain formed between the septin rings, which is rich in $\mathrm{PIP}_{2}$ [103]. Rho1 seems to be necessary late in cytokinesis for secondary septum formation [103].

In $S$. pombe, the role of Rho GTPases in ring assembly or function is poorly understood. We identified the paxillin homolog, Pxl1, which is a Rhol negative modulator and collaborates in the CAR formation and constriction [149]. How Rho1 is negatively regulated by Pxl1? It is likely that Pxl1 modulates a GAP or GEF protein that mediates this regulation. $S$. pombe Cdc42 might also be involved in cytokinesis since the BAR domain-containing protein, Hob3, required for cytokinesis, interacts with the Cdc42-GEF, Gef1 [150]. Deletion of $h o b 3^{+}$causes cell elongation and multiseptation [151]. Hob3 recruits Cdc42 to the division site via the BAR domain. It is not known how the Gef1-Hob3-Cdc42 complex and the spatial restriction of Cdc42 activity works in the CAR constriction. This is a novel mechanism for spatially regulating Cdc42 signaling.

S. pombe Rho3 and Rho4 are also required for cytokinesis. They regulate the polarized secretion of the hydrolytic enzymes that digest the primary septum $[94,97]$. Rho3 regulates the exocyst [94] and might play a general role in secretion, not only during cytokinesis. S. pombe rho $3^{+}$can be substituted for budding yeast $\mathrm{RHO} 3$ but no for other GTPase suggesting that they have a similar function [92]. Rho4 is the only Rho GTPase localized exclusively to the division area [96] and it regulates secretion of lytic enzymes, as Agn1 or Eng1, required for septum degradation [97]. Preliminary results from our laboratory suggest that Rga7 might be a Rho4 GAP that participates in cytokinesis.

\section{RHO PROTEINS AND MATING}

The process of mating is an example of polarized growth in response to an external cue. Haploid yeasts of opposite sexual type are able to mate and generate a diploid zygote which will subsequently undergo meiosis, giving rise to four ascospores. G-coupled receptors (GPCR) detect the presence of the opposite mating type pheromone and activate heterotrimeric $G$ protein which, in turn, activates the mating MAPK pathway. This pathway activates the transcription of a variety of genes necessary for the completion of mating and eventually meiosis. The overall process of mating is quite similar in $S$. cerevisiae and $S$. pombe although there are some differences in the signaling molecules. The formation of a tip projection, called "shmoo," is necessary for mating to take place. Actin and microtubule cytoskeletons are remodeled during this process and allow the "shmoo" growth and proper nuclear orientation for karyogamy. The importance of cytoskeleton in mating suggests a requirement for Rho GTPases function [16]. In fact, Cdc42 plays a critical role in this process. In $S$. cerevisiae, both $\mathrm{Cdc} 24$ and $\mathrm{Cdc} 42$ are necessary for actin polarization and for the activation of the mating MAPK cascade [16]. Bem1 and Ste20 also play a role in mating signaling, and it has been suggested that the correct interaction between $\mathrm{Cdc} 42$, Bem 1 and Ste20 allows efficient pheromone signaling [152]. Cla4 might play a role in mating signaling as a negative regulator of the MAPK pathway, since $c d c 42$ mutants resistant to pheromone treatment are suppressed by cla4 deletion [153]. In S. pombe, 
several $c d c 42$ loss-of-function mutants are sterile (our unpublished results), and both Scd1 and Scd2 deletions lead to conjugation defects. Nevertheless MAPK signaling is not impaired, suggesting that the mating defect in these strains is due to the inability to polarized cell growth [73]. Additionally, the Cdc42 effector Shk1 mediates the transition of the MAPK Byr2 to an activated state [154].

Cdc42 might be also involved in later events during mating, such as localization of the polarisome and cell fusion. ([155-157]; our unpublished results).

Little is known about the role of other Rho GTPases in the yeast mating process. However, Rho1 might have a role in cell wall biogenesis regulation during cell fusion.

\section{CONCLUDING REMARKS}

We have tried to summarize here the relevance of Rho proteins in polarized cell growth. In the last few years, an important understanding of the mechanisms underlying the regulation of polarized growth in yeasts has developed. The role of Rho proteins in the actin cytoskeleton organization has been emphasized as the main determinant in the generation and maintenance of the polarized phenotype. However, Rho proteins also participate in other key pathways for polarized growth independent of the actin cytoskeleton, such as the exocytic machinery, the maintenance of cell integrity, and endocytosis. These different pathways may be more complicated; they receive inputs from the cell cycle, the stress pathways or the nutrient situation, and need to be further studied.

\section{AKNOWLEDGEMENTS}

We thank D. Posner for language revision. This work was supported by grants BFU2007-60675 from the Dirección General de Investigación, MICINN, Spain, and GR231 from Junta de Castilla y León. We apologize for not citing every important paper in this review due to space limitations.

\section{BIBLIOGRAPHY}

1 Mellman, I. and Nelson, W. J. (2008) Coordinated protein sorting, targeting and distribution in polarized cells. Nat Rev Mol Cell Biol. 9, 833-845

2 Moseley, J. B. and Goode, B. L. (2006) The yeast actin cytoskeleton: from cellular function to biochemical mechanism. Microbiol Mol Biol Rev. 70, 605-645

3 Levin, D. E. (2005) Cell wall integrity signaling in Saccharomyces cerevisiae. Microbiol Mol Biol Rev. 69, 262-291

4 Miller, P. J. and Johnson, D. I. (1994) Cdc42p GTPase is involved in controlling polarized growth in Schizosaccharomyces pombe. Mol. Cell. Biol. 14, 1075-1083

5 Arellano, M., Durán, A. and Pérez, P. (1996) Rhol GTPase activates the (13)beta-D-glucan synthase and is involved in Schizosaccharomyces pombe morphogenesis. EMBO J. 15, 4584-4591

6 Wennerberg, K., Rossman, K. L. and Der, C. J. (2005) The Ras superfamily at a glance. J Cell Sci. 118, 843-846

7 Vetter, I. R. and Wittinghofer, A. (2001) The guanine nucleotide-binding switch in three dimensions. Science. 294, 1299-1304

8 Cabib, E., Drgonova, J. and Drgon, T. (1998) Role of small G proteins in yeast cell polarization and wall biosynthesis. Annu Rev Biochem. 67, 307-333 
9 Bishop, A. L. and Hall, A. (2000) Rho GTPases and their effector proteins. Biochem J. 348 Pt 2, 241-255

10 Bos, J. L., Rehmann, H. and Wittinghofer, A. (2007) GEFs and GAPs: critical elements in the control of small $\mathrm{G}$ proteins. Cell. 129, 865-877

11 Garcia, P., Tajadura, V., Garcia, I. and Sanchez, Y. (2006) Role of Rho GTPases and Rho-GEFs in the regulation of cell shape and integrity in fission yeast. Yeast. 23, 1031-1043

12 Hirota, K., Tanaka, K., Ohta, K. and Yamamoto, M. (2003) Geflp and Scd1p, the Two GDP-GTP exchange factors for Cdc42p, form a ring structure that shrinks during cytokinesis in Schizosaccharomyces pombe. Mol Biol Cell. 14, 3617-3627

13 Coll, P. M., Trillo, Y., Ametzazurra, A. and Perez, P. (2003) Geflp, a new guanine nucleotide exchange factor for $\mathrm{Cdc} 42 \mathrm{p}$, regulates polarity in Schizosaccharomyces pombe. Mol Biol Cell. 14, 313-323

14 DerMardirossian, C. and Bokoch, G. M. (2005) GDIs: central regulatory molecules in Rho GTPase activation. Trends Cell Biol. 15, 356-363

15 Chang, F. and Peter, M. (2003) Yeasts make their mark. Nat Cell Biol. 5, 294299

16 Park, H. O. and Bi, E. (2007) Central roles of small GTPases in the development of cell polarity in yeast and beyond. Microbiol Mol Biol Rev. 71, 48-96

17 Nern, A. and Arkowitz, R. A. (2000) Nucleocytoplasmic shuttling of the Cdc42p exchange factor Cdc24p. J Cell Biol. 148, 1115-1122

18 Shimada, Y., Gulli, M. P. and Peter, M. (2000) Nuclear sequestration of the exchange factor Cdc24 by Far1 regulates cell polarity during yeast mating. Nat Cell Biol. 2, 117-124

19 Cole, K. C., Barbour, J. E., Midkiff, J. F., Marble, B. M. and Johnson, D. I. (2009) Multiple proteins and phosphorylations regulate Saccharomyces cerevisiae Cdc24p localization. FEBS Lett. 583, 3339-3343

20 Wai, S. C., Gerber, S. A. and Li, R. (2009) Multisite phosphorylation of the guanine nucleotide exchange factor $\mathrm{Cdc} 24$ during yeast cell polarization. PLoS One. 4, e6563

21 McCusker, D., Denison, C., Anderson, S., Egelhofer, T. A., Yates, J. R., 3rd, Gygi, S. P. and Kellogg, D. R. (2007) Cdk1 coordinates cell-surface growth with the cell cycle. Nat Cell Biol. 9, 506-515

22 Mionnet, C., Bogliolo, S. and Arkowitz, R. A. (2008) Oligomerization regulates the localization of $\mathrm{Cdc} 24$, the Cdc42 activator in Saccharomyces cerevisiae. J Biol Chem. 283, 17515-17530

23 Kozubowski, L., Saito, K., Johnson, J. M., Howell, A. S., Zyla, T. R. and Lew, D. J. (2008) Symmetry-breaking polarization driven by a Cdc42p GEF-PAK complex. Curr Biol. 18, 1719-1726

24 Bose, I., Irazoqui, J. E., Moskow, J. J., Bardes, E. S., Zyla, T. R. and Lew, D. J. (2001) Assembly of scaffold-mediated complexes containing Cdc42p, the exchange factor Cdc24p, and the effector Cla4p required for cell cycle-regulated phosphorylation of Cdc24p. J Biol Chem. 276, 7176-7186

25 Gulli, M. P., Jaquenoud, M., Shimada, Y., Niederhauser, G., Wiget, P. and Peter, M. (2000) Phosphorylation of the Cdc42 exchange factor Cdc24 by the PAK-like kinase Cla4 may regulate polarized growth in yeast. Mol Cell. 6, 1155-1167

26 Irazoqui, J. E., Howell, A. S., Theesfeld, C. L. and Lew, D. J. (2005) Opposing roles for actin in Cdc42p polarization. Mol Biol Cell. 16, 1296-1304 
27 Howell, A. S., Savage, N. S., Johnson, S. A., Bose, I., Wagner, A. W., Zyla, T. R., Nijhout, H. F., Reed, M. C., Goryachev, A. B. and Lew, D. J. (2009) Singularity in polarization: rewiring yeast cells to make two buds. Cell. 139, 731-743

28 Slaughter, B. D., Das, A., Schwartz, J. W., Rubinstein, B. and Li, R. (2009) Dual modes of cdc42 recycling fine-tune polarized morphogenesis. Dev Cell. 17, 823-835

29 Knaus, M., Pelli-Gulli, M. P., van Drogen, F., Springer, S., Jaquenoud, M. and Peter, M. (2007) Phosphorylation of Bem2p and Bem3p may contribute to local activation of Cdc42p at bud emergence. Embo J. 26, 4501-4513

30 Caviston, J. P., Longtine, M., Pringle, J. R. and Bi, E. (2003) The role of Cdc42p GTPase-activating proteins in assembly of the septin ring in yeast. Mol Biol Cell. 14, 4051-4066

31 Sopko, R., Huang, D., Smith, J. C., Figeys, D. and Andrews, B. J. (2007) Activation of the Cdc42p GTPase by cyclin-dependent protein kinases in budding yeast. EMBO J. 26, 4487-4500

32 Tiedje, C., Sakwa, I., Just, U. and Hofken, T. (2008) The Rho GDI Rdil regulates Rho GTPases by distinct mechanisms. Mol Biol Cell. 19, 2885-2896

33 Lamson, R. E., Winters, M. J. and Pryciak, P. M. (2002) Cdc42 regulation of kinase activity and signaling by the yeast p21-activated kinase Ste20. Mol Cell Biol. 22, 2939-2951

34 Peter, M., Neiman, A. M., Park, H. O., van Lohuizen, M. and Herskowitz, I. (1996) Functional analysis of the interaction between the small GTP binding protein Cdc42 and the Ste20 protein kinase in yeast. Embo J. 15, 7046-7059

35 Leberer, E., Wu, C., Leeuw, T., Fourest-Lieuvin, A., Segall, J. E. and Thomas, D. Y. (1997) Functional characterization of the Cdc42p binding domain of yeast Ste20p protein kinase. Embo J. 16, 83-97

36 Benton, B. K., Tinkelenberg, A., Gonzalez, I. and Cross, F. R. (1997) Cla4p, a Saccharomyces cerevisiae Cdc42p-activated kinase involved in cytokinesis, is activated at mitosis. Mol Cell Biol. 17, 5067-5076

37 Wu, C., Lee, S. F., Furmaniak-Kazmierczak, E., Cote, G. P., Thomas, D. Y. and Leberer, E. (1996) Activation of myosin-I by members of the Ste20p protein kinase family. J Biol Chem. 271, 31787-31790

38 Wu, C., Lytvyn, V., Thomas, D. Y. and Leberer, E. (1997) The phosphorylation site for Ste20p-like protein kinases is essential for the function of myosin-I in yeast. J Biol Chem. 272, 30623-30626

39 Lechler, T., Jonsdottir, G. A., Klee, S. K., Pellman, D. and Li, R. (2001) A twotiered mechanism by which Cdc42 controls the localization and activation of an Arp2/3activating motor complex in yeast. J Cell Biol. 155, 261-270.

40 Buttery, S. M., Yoshida, S. and Pellman, D. (2007) Yeast formins Bni1 and Bnr1 utilize different modes of cortical interaction during the assembly of actin cables. Mol Biol Cell. 18, 1826-1838

41 Dong, Y., Pruyne, D. and Bretscher, A. (2003) Formin-dependent actin assembly is regulated by distinct modes of Rho signaling in yeast. J Cell Biol. 161, 1081-1092

42 Gao, L. and Bretscher, A. (2009) Polarized growth in budding yeast in the absence of a localized formin. Mol Biol Cell. 20, 2540-2548

43 Brown, J. L., Jaquenoud, M., Gulli, M. P., Chant, J. and Peter, M. (1997) Novel Cdc42-binding proteins Gic1 and Gic2 control cell polarity in yeast. Genes Dev. 11, 2972-2982

44 Chen, G.-C., Kim, Y. J. and Chan, C. S. M. (1997) The Cdc42 GTPaseassociated proteins Gic1 and Gic2 are required for polarized cell growth in Saccharomyces cerevisiae. Gen.Dev. 11, 2958-2971 
45 Orlando, K., Zhang, J., Zhang, X., Yue, P., Chiang, T., Bi, E. and Guo, W. (2008) Regulation of Gic2 localization and function by phosphatidylinositol 4,5bisphosphate during the establishment of cell polarity in budding yeast. J Biol Chem. 283, 14205-14212

46 Iwase, M., Luo, J., Nagaraj, S., Longtine, M., Kim, H. B., Haarer, B. K., Caruso, C., Tong, Z., Pringle, J. R. and Bi, E. (2006) Role of a Cdc42p effector pathway in recruitment of the yeast septins to the presumptive bud site. Mol Biol Cell. 17, 11101125

47 Cvrcková, F., De Virgilio, C., Manser, E., Pringle, J. R. and Nasmyth, K. (1995) Ste20-like protein kinases are required for normal localization of cell growth and for cytokinesis in budding yeast. Genes Dev. 9, 1817-1830

48 Kadota, J., Yamamoto, T., Yoshiuchi, S., Bi, E. and Tanaka, K. (2004) Septin ring assembly requires concerted action of polarisome components, a PAK kinase Cla4p, and the actin cytoskeleton in Saccharomyces cerevisiae. Mol Biol Cell. 15, 5329-5345

49 Versele, M. and Thorner, J. (2004) Septin collar formation in budding yeast requires GTP binding and direct phosphorylation by the PAK, Cla4. J Cell Biol. 164, $701-715$

50 Zhang, X., Bi, E., Novick, P., Du, L., Kozminski, K. G., Lipschutz, J. H. and Guo, W. (2001) Cdc42 interacts with the exocyst and regulates polarized secretion. J Biol Chem. 276, 46745-46750

51 Adamo, J. E., Moskow, J. J., Gladfelter, A. S., Viterbo, D., Lew, D. J. and Brennwald, P. J. (2001) Yeast Cdc42 functions at a late step in exocytosis, specifically during polarized growth of the emerging bud. J Cell Biol. 155, 581-592

52 Roumanie, O., Wu, H., Molk, J. N., Rossi, G., Bloom, K. and Brennwald, P. (2005) Rho GTPase regulation of exocytosis in yeast is independent of GTP hydrolysis and polarization of the exocyst complex. J Cell Biol. 170, 583-594

53 Zhang, X., Orlando, K., He, B., Xi, F., Zhang, J., Zajac, A. and Guo, W. (2008) Membrane association and functional regulation of Sec3 by phospholipids and Cdc42. J Cell Biol. 180, 145-158

54 Guo, W., Tamanoi, F. and Novick, P. (2001) Spatial regulation of the exocyst complex by Rho1 GTPase. Nat Cell Biol. 3, 353-360.

55 Hutagalung, A. H., Coleman, J., Pypaert, M. and Novick, P. J. (2009) An internal domain of Exo70p is required for actin-independent localization and mediates assembly of specific exocyst components. Mol Biol Cell. 20, 153-163

56 Robinson, N. G., Guo, L., Imai, J., Toh, E. A., Matsui, Y. and Tamanoi, F. (1999) Rho3 of Saccharomyces cerevisiae, which regulates the actin cytoskeleton and exocytosis, is a GTPase which interacts with Myo2 and Exo70. Mol Cell Biol. 19, 3580-3587.

$57 \mathrm{Wu}, \mathrm{H}$. , Rossi, G. and Brennwald, P. (2008) The ghost in the machine: small GTPases as spatial regulators of exocytosis. Trends Cell Biol. 18, 397-404

58 Brennwald, P. and Rossi, G. (2007) Spatial regulation of exocytosis and cell polarity: yeast as a model for animal cells. FEBS Lett. 581, 2119-2124

59 Hayles, J. and Nurse, P. (2001) A journey into space. Nat Rev Mol Cell Biol. 2, 647-656

60 Castagnetti, S., Novak, B. and Nurse, P. (2007) Microtubules offset growth site from the cell centre in fission yeast. J Cell Sci. 120, 2205-2213

61 Martin, S. G. (2009) Microtubule-dependent cell morphogenesis in the fission yeast. Trends Cell Biol. 19, 447-454 
62 Terenna, C. R., Makushok, T., Velve-Casquillas, G., Baigl, D., Chen, Y., Bornens, M., Paoletti, A., Piel, M. and Tran, P. T. (2008) Physical mechanisms redirecting cell polarity and cell shape in fission yeast. Curr Biol. 18, 1748-1753

63 Minc, N., Bratman, S. V., Basu, R. and Chang, F. (2009) Establishing new sites of polarization by microtubules. Curr Biol. 19, 83-94

64 Mata, J. and Nurse, P. (1997) teal and the microtubular cytoskeleton are important for generating global spatial order within the fission yeast. Cell. 89, 939-950

65 Snaith, H. A. and Sawin, K. E. (2003) Fission yeast mod5p regulates polarized growth through anchoring of tealp at cell tips. Nature. 423, 647-651

66 Snaith, H. A., Samejima, I. and Sawin, K. E. (2005) Multistep and multimode cortical anchoring of tealp at cell tips in fission yeast. Embo J. 24, 3690-3699

67 Martin, S. G., McDonald, W. H., Yates, J. R., 3rd and Chang, F. (2005) Tea4p links microtubule plus ends with the formin for $3 p$ in the establishment of cell polarity. Dev Cell. 8, 479-491

68 Feierbach, B. and Chang, F. (2001) Roles of the fission yeast formin for $3 p$ in cell polarity, actin cable formation and symmetric cell division. Curr Biol. 11, 16561665

69 Martin, S. G., Rincon, S. A., Basu, R., Perez, P. and Chang, F. (2007) Regulation of the formin for3p by cdc42p and bud6p. Mol Biol Cell. 18, 4155-4167

70 Glynn, J. M., Lustig, R. J., Berlin, A. and Chang, F. (2001) Role of bud6p and tea $1 p$ in the interaction between actin and microtubules for the establishment of cell polarity in fission yeast. Curr Biol. 11, 836-845.

71 Rincon, S. A., Ye, Y., Villar-Tajadura, M. A., Santos, B., Martin, S. G. and Perez, P. (2009) Pob1 participates in the Cdc42 regulation of fission yeast actin cytoskeleton. Mol Biol Cell. 20, 4390-4399

72 Merla, A. and Johnson, D. I. (2000) The Cdc42p GTPase is targeted to the site of cell division in the fission yeast Schizosaccharomyces pombe. Eur J Cell Biol. 79, 469-477

73 Chang, E. C., Barr, M., Wang, Y., Jung, V., Xu, H. P. and Wigler, M. H. (1994) Cooperative interaction of $S$. pombe proteins required for mating and morphogenesis. Cell. 79, 131-141

74 Li, Y. C., Chen, C. R. and Chang, E. C. (2000) Fission yeast Ras1 effector Scd1 interacts with the spindle and affects its proper formation. Genetics. 156, 995-1004

75 Fukui, Y., Kozasa, T., Kaziro, Y., Yakeda, T. and Yamamoto, M. (1986) Role of a ras homolog in the life cycle of Schizosaccharomyces pombe. Cell. 44, 329-336

76 Papadaki, P., Pizon, V., Onken, B. and Chang, E. C. (2002) Two ras pathways in fission yeast are differentially regulated by two ras guanine nucleotide exchange factors. Mol Cell Biol. 22, 4598-4606

77 Murray, J. M. and Johnson, D. I. (2001) The Cdc42p GTPase and its regulators Nrflp and Scdlp are involved in endocytic trafficking in the fission yeast Schizosaccharomyces pombe. J Biol Chem. 276, 3004-3009

$78 \mathrm{Li}, \mathrm{Y}$. and Chang, E. C. (2003) Schizosaccharomyces pombe Ras1 effector, Scd1, interacts with Klp5 and Klp6 kinesins to mediate cytokinesis. Genetics. 165, 477488

79 Endo, M., Shirouzu, M. and Yokoyama, S. (2003) The Cdc42 binding and scaffolding activities of the fission yeast adaptor protein Scd2. J Biol Chem. 278, 843852

80 Das, M., Wiley, D. J., Chen, X., Shah, K. and Verde, F. (2009) The conserved NDR kinase Orb6 controls polarized cell growth by spatial regulation of the small GTPase Cdc42. Curr Biol. 19, 1314-1319 
81 Tatebe, H., Nakano, K., Maximo, R. and Shiozaki, K. (2008) Pom1 DYRK regulates localization of the Rga4 GAP to ensure bipolar activation of Cdc42 in fission yeast. Curr Biol. 18, 322-330

82 Das, M., Wiley, D. J., Medina, S., Vincent, H. A., Larrea, M., Oriolo, A. and Verde, F. (2007) Regulation of cell diameter, For3p localization, and cell symmetry by fission yeast Rho-GAP Rga4p. Mol Biol Cell. 18, 2090-2101

83 Bahler, J. and Pringle, J. R. (1998) Pom1p, a fission yeast protein kinase that provides positional information for both polarized growth and cytokinesis. Genes Dev. $12,1356-1370$

84 Marcus, S., Polverino, A., Chang, E., Robbins, D., Cobb, M. H. and Wigler, M. (1995) Shk1, a homolog of the Saccharomyces cerevisiae Ste20 and mammalian p65PAK protein kinases, is a component of a Ras/Cdc42 signaling module in the fission yeast Schizosaccharomyces pombe. Proc. Natl. Acad. Sci. USA. 92, 6180-6184

85 Ottilie, S., Miller, P. J., Johnson, D. I., Creasy, C. L., Sells, M. A., Bagrodia, S., Forsburg, S. and Chernoff, J. (1995) Fission yeast pakl ${ }^{+}$encodes a protein kinase that interacts with Cdc42p and is involved in the control of cell polarity and mating. EMBO J. 14, 5908-5919

86 Kim, H., Yang, P., Catanuto, P., Verde, F., Lai, H., Du, H., Chang, F. and Marcus, S. (2003) The kelch repeat protein, Tea1, is a potential substrate target of the p21-activated kinase, Shk1, in the fission yeast, Schizosaccharomyces pombe. J Biol Chem. 278, 30074-30082

87 Loo, T. H. and Balasubramanian, M. (2008) Schizosaccharomyces pombe Pakrelated protein, Pak1p/Orb2p, phosphorylates myosin regulatory light chain to inhibit cytokinesis. J Cell Biol. 183, 785-793

88 Yang, P., Kansra, S., Pimental, R. A., Gilbreth, M. and Marcus, S. (1998) Cloning and characterization of shk2, a gene encoding a novel p21-activated protein kinase from fission yeast. J Biol Chem. 273, 18481-18489

89 Sells, M. A., Barratt, J. T., Caviston, J., Ottilie, S., Leberer, E. and Chernoff, J. (1998) Characterization of Pak2p, a pleckstrin homology domain-containing, p21activated protein kinase from fission yeast. J Biol Chem. 273, 18490-18498

90 Merla, A. and Johnson, D. I. (2001) The Schizosaccharomyces pombe Cdc42p GTPase signals through Pak2p and the Mkh1p-Pek1p-Spm1p MAPK pathway . Curr Genet. 39, 205-209

91 Madrid, M., Soto, T., Khong, H. K., Franco, A., Vicente, J., Pérez, P., Gacto, M. and Cansado, J. (2006) Stress-induced response, localization, and regulation of the Pmk1 cell integrity pathway in Schizosaccharomyces pombe. J Biol Chem. 281, 20332043

92 Nakano, K., Imai, J., Arai, R., Toh, E. A., Matsui, Y. and Mabuchi, I. (2002) The small GTPase Rho3 and the diaphanous/formin For3 function in polarized cell growth in fission yeast. J Cell Sci. 115, 4629-4639

93 Arellano, M., Duran, A. and Perez, P. (1997) Localisation of the Schizosaccharomyces pombe rho1p GTPase and its involvement in the organisation of the actin cytoskeleton. J Cell Sci. 110 ( Pt 20), 2547-2555

94 Wang, H., Tang, X. and Balasubramanian, M. K. (2003) Rho3p Regulates Cell Separation by Modulating Exocyst Function in Schizosaccharomyces pombe. Genetics. $164,1323-1331$

95 Wang, H., Tang, X., Liu, J., Trautmann, S., Balasundaram, D., McCollum, D. and Balasubramanian, M. K. (2002) The Multiprotein Exocyst Complex Is Essential for Cell Separation in Schizosaccharomyces pombe. Mol Biol Cell. 13, 515-529. 
96 Santos, B., Gutierrez, J., Calonge, T. M. and Perez, P. (2003) Novel Rho GTPase Involved in Cytokinesis and Cell Wall Integrity in the Fission Yeast Schizosaccharomyces pombe. Eukaryot Cell. 2, 521-533

97 Santos, B., Martin-Cuadrado, A. B., Vazquez de Aldana, C. R., del Rey, F. and Perez, P. (2005) Rho4 GTPase is involved in secretion of glucanases during fission yeast cytokinesis. Eukaryot Cell. 4, 1639-1645

98 Qadota, H., Python, C. P., Inoue, S. B., Arisawa, M., Anraku, Y., Zheng, Y., Watanabe, T., Levin, D. E. and Ohya, Y. (1996) Identification of yeast Rho1p GTPase as a regulatory subunit of 1,3-beta-glucan synthase. Science. 272, 279-281

99 Ozaki, K., Tanaka, K., Imamura, H., Hihara, T., Kameyama, T., Nonaka, H., Hirano, H., Matsuura, Y. and Takai, Y. (1996) Rom1p and Rom2p are GDP/GTP exchange proteins (GEPs) for the Rholp small GTP binding protein in Saccharomyces cerevisiae. EMBO J. 15, 2196-2207

100 Schmelzle, T., Helliwell, S. B. and Hall, M. N. (2002) Yeast protein kinases and the RHO1 exchange factor TUS1 are novel components of the cell integrity pathway in yeast. Mol Cell Biol. 22, 1329-1339

101 Kono, K., Nogami, S., Abe, M., Nishizawa, M., Morishita, S., Pellman, D. and Ohya, Y. (2008) G1/S cyclin-dependent kinase regulates small GTPase Rholp through phosphorylation of RhoGEF Tus1p in Saccharomyces cerevisiae. Mol Biol Cell. 19, 1763-1771

102 Yoshida, S., Kono, K., Lowery, D. M., Bartolini, S., Yaffe, M. B., Ohya, Y. and Pellman, D. (2006) Polo-like kinase Cdc5 controls the local activation of Rho1 to promote cytokinesis. Science. 313, 108-111

103 Yoshida, S., Bartolini, S. and Pellman, D. (2009) Mechanisms for concentrating Rho1 during cytokinesis. Genes Dev. 23, 810-823

104 Cid, V. J., Cenamor, R., Sánchez, M. and Nombela, C. (1998) A mutation in the Rho1-GAP-encoding gene BEM2 of Saccharomyces cerevisiae affects morphogenesis and cell wall functionality. Microbiology. 144 ( Pt 1), 25-36

105 Martín, H., Rodríguez-Pachón, J. M., Ruiz, C., Nombela, C. and Molina, M. (2000) Regulatory mechanisms for modulation of signaling through the cell integrity Slt2-mediated pathway in Saccharomyces cerevisiae. J Biol Chem. 275, 1511-1519

106 Schmidt, A. and Hall, A. (2002) Guanine nucleotide exchange factors for Rho GTPases: turning on the switch. Genes Dev. 16, 1587-1609

107 Watanabe, D., Abe, M. and Ohya, Y. (2001) Yeast Lrg1p acts as a specialized RhoGAP regulating 1,3-beta-glucan synthesis. Yeast. 18, 943-951

108 Nakano, K. and Mabuchi, I. (1995) Isolation and sequencing of two cDNA clones encoding Rho proteins from the fission yeast Schizosaccharomyces pombe. Gene. 155, 119-122

109 Nakano, K., Arai, R. and Mabuchi, I. (1997) The small GTP-binding protein Rho1 is a multifunctional protein that regulates actin localization, cell polarity, and septum formation in the fission yeast Schizosaccharomyces pombe. Genes Cells. 2, 679694

110 Tajadura, V., Garcia, B., Garcia, I., Garcia, P. and Sanchez, Y. (2004) Schizosaccharomyces pombe Rgf3p is a specific Rho1 GEF that regulates cell wall $\beta$ glucan biosynthesis through the GTPase Rho1p. J Cell Sci. 117, 6163-6174

111 Morrell-Falvey, J. L., Ren, L., Feoktistova, A., Haese, G. D. and Gould, K. L. (2005) Cell wall remodeling at the fission yeast cell division site requires the Rho-GEF Rgf3p. J Cell Sci. 118, 5563-5573 
112 Mutoh, T., Nakano, K. and Mabuchi, I. (2005) Rho1-GEFs Rgf1 and Rgf2 are involved in formation of cell wall and septum, while Rgf3 is involved in cytokinesis in fission yeast. Genes Cells. 10, 1189-1202

113 García, P., Tajadura, V., García, I. and Sánchez, Y. (2006) Rgflp is a specific Rho1-GEF that coordinates cell polarization with cell wall biogenesis in fission yeast. Mol Biol Cell. 17, 1620-1631

114 García, P., Tajadura, V. and Sánchez, Y. (2009) The Rholp exchange factor Rgflp signals upstream from the Pmk1 mitogen-activated protein kinase pathway in fission yeast. Mol Biol Cell. 20, 721-731

115 Nakano, K., Mutoh, T. and Mabuchi, I. (2001) Characterization of GTPaseactivating proteins for the function of the Rho-family small GTPases in the fission yeast Schizosaccharomyces pombe. Genes Cells. 6, 1031-1042.

116 Calonge, T. M., Arellano, M., Coll, P. M. and Perez, P. (2003) Rga5p is a specific Rholp GTPase-activating protein that regulates cell integrity in Schizosaccharomyces pombe. Mol Microbiol. 47, 507-518

117 Yang, P., Qyang, Y., Bartholomeusz, G., Zhou, X. and Marcus, S. (2003) The novel Rho GTPase-activating protein family protein, Rga8, provides a potential link between Cdc42/p21-activated kinase and Rho signaling pathways in the fission yeast, Schizosaccharomyces pombe. J Biol Chem. 278, 48821-48830

118 Nakano, K., Mutoh, T., Arai, R. and Mabuchi, I. (2003) The small GTPase Rho4 is involved in controlling cell morphology and septation in fission yeast. Genes Cells. 8, $357-370$

119 Hirata, D., Nakano, K., Fukui, M., Takenaka, H., Miyakawa, T. and Mabuchi, I. (1998) Genes that cause aberrant cell morphology by overexpression in fission yeast: a role of a small GTP-binding protein Rho2 in cell morphogenesis. J Cell Sci. 111 ( Pt 2), 149-159

120 Calonge, T. M., Nakano, K., Arellano, M., Arai, R., Katayama, S., Toda, T., Mabuchi, I. and Pérez, P. (2000) Schizosaccharomyces pombe rho2p GTPase regulates cell wall alpha-glucan biosynthesis through the protein kinase pck2p. Mol Biol Cell. 11, 4393-4401

121 Arellano, M., Valdivieso, M. H., Calonge, T. M., Coll, P. M., Durán, A. and Pérez, P. (1999) Schizosaccharomyces pombe protein kinase C homologues, pck1p and pck $2 p$, are targets of rholp and rho2p and differentially regulate cell integrity. J Cell Sci. 112 ( Pt 20), 3569-3578

122 Villar-Tajadura, M. A., Coll, P. M., Madrid, M., Cansado, J., Santos, B. and Pérez, P. (2008) Rga2 is a Rho2 GAP that regulates morphogenesis and cell integrity in S. pombe. Mol Microbiol. 70, 867-881

123 Lesage, G. and Bussey, H. (2006) Cell wall assembly in Saccharomyces cerevisiae. Microbiol Mol Biol Rev. 70, 317-343

124 Philip, B. and Levin, D. E. (2001) Wsc1 and Mid2 are cell surface sensors for cell wall integrity signaling that act through Rom2, a guanine nucleotide exchange factor for Rho1. Mol Cell Biol. 21, 271-280.

125 Facchinetti, V., Ouyang, W., Wei, H., Soto, N., Lazorchak, A., Gould, C., Lowry, C., Newton, A. C., Mao, Y., Miao, R. Q., Sessa, W. C., Qin, J., Zhang, P., Su, B. and Jacinto, E. (2008) The mammalian target of rapamycin complex 2 controls folding and stability of Akt and protein kinase C. EMBO J. 27, 1932-1943

126 Pujol, N., Bonet, C., Vilella, F., Petkova, M. I., Mozo-Villarias, A. and de la Torre-Ruiz, M. A. (2009) Two proteins from Saccharomyces cerevisiae: Pfy1 and Pkc1, play a dual role in activating actin polymerization and in increasing cell viability in the adaptive response to oxidative stress. FEMS Yeast Res 
127 Krause, S. A. and Gray, J. V. (2002) The protein kinase C pathway is required for viability in quiescence in Saccharomyces cerevisiae. Curr Biol. 12, 588-593

128 Denis, V. and Cyert, M. S. (2005) Molecular analysis reveals localization of Saccharomyces cerevisiae protein kinase $\mathrm{C}$ to sites of polarized growth and Pkc1p targeting to the nucleus and mitotic spindle. Eukaryot Cell. 4, 36-45

129 Flynn, P., Mellor, H., Casamassima, A. and Parker, P. J. (2000) Rho GTPase control of protein kinase C-related protein kinase activation by 3-phosphoinositidedependent protein kinase. J Biol Chem. 275, 11064-11070

130 Inagaki, M., Schmelzle, T., Yamaguchi, K., Irie, K., Hall, M. N. and Matsumoto, K. (1999) PDK1 homologs activate the Pkc1-mitogen-activated protein kinase pathway in yeast. Mol Cell Biol. 19, 8344-8352

131 Niederberger, C. and Schweingruber, M. E. (1999) A Schizosaccharomyces pombe gene, ksgl, that shows structural homology to the human phosphoinositidedependent protein kinase PDK1, is essential for growth, mating and sporulation. Mol Gen Genet. 261, 177-183.

132 Ma, Y., Kuno, T., Kita, A., Asayama, Y. and Sugiura, R. (2006) Rho2 is a target of the farnesyltransferase Cpp1 and acts upstream of Pmk1 mitogen-activated protein kinase signaling in fission yeast. Mol Biol Cell. 17, 5028-5037

133 Barba, G., Soto, T., Madrid, M., Núñez, A., Vicente, J., Gacto, M. and Cansado, J. (2008) Activation of the cell integrity pathway is channelled through diverse signalling elements in fission yeast. Cell Signal. 20, 748-757

134 Toda, T., Dhut, S., Superti-Furga, G., Gotoh, Y., Nishida, E., Sugiura, R. and Kuno, T. (1996) The fission yeast pmkl+ gene encodes a novel mitogen-activated protein kinase homolog which regulates cell integrity and functions coordinately with the protein kinase $C$ pathway. Mol Cell Biol. 16, 6752-6764

135 Sengar, A. S., Markley, N. A., Marini, N. J. and Young, D. (1997) Mkh1, a MEK kinase required for cell wall integrity and proper response to osmotic and temperature stress in Schizosaccharomyces pombe. Mol Cell Biol. 17, 3508-3519

136 Sugiura, R., Toda, T., Dhut, S., Shuntoh, H. and Kuno, T. (1999) The MAPK kinase Pek1 acts as a phosphorylation-dependent molecular switch. Nature. 399, 479483

137 Loewith, R., Hubberstey, A. and Young, D. (2000) Skh1, the MEK component of the mkh1 signaling pathway in Schizosaccharomyces pombe. J Cell Sci. 113 ( Pt 1), $153-160$

138 Zaitsevskaya-Carter, T. and Cooper, J. A. (1997) Spm1, a stress-activated MAP kinase that regulates morphogenesis in S.pombe. EMBO J. 16, 1318-1331

139 Bone, N., Millar, J. B., Toda, T. and Armstrong, J. (1998) Regulated vacuole fusion and fission in Schizosaccharomyces pombe: an osmotic response dependent on MAP kinases. Curr Biol. 8, 135-144

140 Takada, H., Nishimura, M., Asayama, Y., Mannse, Y., Ishiwata, S., Kita, A., Doi, A., Nishida, A., Kai, N., Moriuchi, S., Tohda, H., Giga-Hama, Y., Kuno, T. and Sugiura, R. (2007) Atf1 is a target of the mitogen-activated protein kinase Pmk1 and regulates cell integrity in fission yeast. Mol Biol Cell. 18, 4794-4802

141 Wilkinson, M. G., Samuels, M., Takeda, T., Toone, W. M., Shieh, J. C., Toda, T., Millar, J. B. and Jones, N. (1996) The Atfl transcription factor is a target for the Sty1 stress-activated MAP kinase pathway in fission yeast. Genes Dev. 10, 2289-2301 142 Feierbach, B. and Chang, F. (2001) Cytokinesis and the contractile ring in fission yeast. Curr Opin Microbiol. 4, 713-719

143 Balasubramanian, M. K., Bi, E. and Glotzer, M. (2004) Comparative analysis of cytokinesis in budding yeast, fission yeast and animal cells. Curr Biol. 14, R806-818 
144 Pollard, T. D. (2008) Progress towards understanding the mechanism of cytokinesis in fission yeast. Biochem Soc Trans. 36, 425-430

145 Roberts-Galbraith, R. H. and Gould, K. L. (2008) Stepping into the ring: the SIN takes on contractile ring assembly. Genes Dev. . 22, 3082-3088

146 Krapp, A. and Simanis, V. (2008) An overview of the fission yeast septation initiation network (SIN). Biochem Soc Trans. 36, 411-415

147 Hachet, O. and Simanis, V. (2008) Midlp/anillin and the septation initiation network orchestrate contractile ring assembly for cytokinesis. Genes Dev. 22, 32053216

148 Tolliday, N., VerPlank, L. and Li, R. (2002) Rho1 directs formin-mediated actin ring assembly during budding yeast cytokinesis. Curr Biol. 12, 1864-1870

149 Pinar, M., Coll, P. M., Rincon, S. A. and Perez, P. (2008) Schizosaccharomyces pombe Pxl1 is a paxillin homologue that modulates Rhol activity and participates in cytokinesis. Mol Biol Cell. 19, 1727-1738

150 Coll, P. M., Rincon, S. A., Izquierdo, R. A. and Perez, P. (2007) Hob3p, the fission yeast ortholog of human BIN3, localizes Cdc42p to the division site and regulates cytokinesis. EMBO J. 26, 1865-1877

151 Routhier, E. L., Burn, T. C., Abbaszade, I., Summers, M., Albright, C. F. and Prendergast, G. C. (2001) Human BIN3 complements the F-actin localization defects caused by loss of Hob3p, the fission yeast homolog of Rvs161p. J Biol Chem. 276, 21670-21677

152 Yamaguchi, Y., Ota, K. and Ito, T. (2007) A novel Cdc42-interacting domain of the yeast polarity establishment protein Bem1. Implications for modulation of mating pheromone signaling. J Biol Chem. 282, 29-38

153 Heinrich, M., Kohler, T. and Mosch, H. U. (2007) Role of Cdc42-Cla4 interaction in the pheromone response of Saccharomyces cerevisiae. Eukaryot Cell. 6, 317-327

154 Tu, H., Barr, M., Dong, D. L. and Wigler, M. (1997) Multiple regulatory domains on the Byr2 protein kinase. Mol Cell Biol. 17, 5876-5887

155 Nelson, B., Parsons, A. B., Evangelista, M., Schaefer, K., Kennedy, K., Ritchie, S., Petryshen, T. L. and Boone, C. (2004) Fus1p interacts with components of the Hog $1 \mathrm{p}$ mitogen-activated protein kinase and Cdc42p morphogenesis signaling pathways to control cell fusion during yeast mating. Genetics. 166, 67-77

156 Barale, S., McCusker, D. and Arkowitz, R. A. (2004) The exchange factor $\mathrm{Cdc} 24$ is required for cell fusion during yeast mating. Eukaryot Cell. 3, 1049-1061

157 Rida, P. C. and Surana, U. (2005) Cdc42-dependent localization of polarisome component Spa2 to the incipient bud site is independent of the GDP/GTP exchange factor Cdc24. Eur J Cell Biol. 84, 939-949 
TABLE 1. Rho GEFs and GAPs in $S$. cerevisiae and $S$. pombe

\begin{tabular}{|c|c|c|c|c|}
\hline GTPase & S. cerevisiae & & S. pombe & \\
\hline & GEF & GAP & GEF & GAP \\
\hline Cdc42 & $\mathrm{Cdc} 24$ & $\begin{array}{l}\text { Rga1 } \\
\text { Rga2 } \\
\text { Bem2 } \\
\text { Bem3 }\end{array}$ & $\begin{array}{l}\text { Scd1 } \\
\text { Gef1 }\end{array}$ & Rga4 \\
\hline Rho1 & $\begin{array}{l}\text { Rom1 } \\
\text { Rom2 } \\
\text { Tus1 }\end{array}$ & $\begin{array}{l}\text { Lrg1 } \\
\text { Bem2 } \\
\text { Sac7 } \\
\text { Bag7 }\end{array}$ & $\begin{array}{l}\text { Rgf1 } \\
\text { Rgf2 } \\
\text { Rgf3 }\end{array}$ & $\begin{array}{l}\text { Rga1 } \\
\text { Rga5 } \\
\text { Rga8 }\end{array}$ \\
\hline Rho2 & $?$ & $?$ & $?$ & $\begin{array}{l}\text { Rga2 } \\
\text { Rga4 } \\
\text { Rga7 }\end{array}$ \\
\hline Rho3 & $?$ & Rgd1 & $?$ & ? \\
\hline Rho4 & $?$ & $\operatorname{Rgd} 1$ & $?$ & Rga7 \\
\hline Rho5 & ? & Rgd2 & ? & ? \\
\hline
\end{tabular}

FIGURE LEGENDS

Figure 1. The GTPase cycle

Inactive GDP-bound small GTPases are activated by GEFs, which promote the release of GDP and allow its replacement by GTP. Active GTP-bound small GTPases can then promote the activation of different effectors until they return to their GDP-bound inactive state upon hydrolysis of the GTP into GDP, which is catalyzed by GAPs. Guanine nucleotide-dissociation inhibitors (GDIs) extract Rho GTPases from the membranes.

Figure 2. Schematic representation of $S$. cerevisiae and $S$. pombe polarized growth establishment and Cdc42 localization. A) Cdc24 is recruited by GTP-Rsr1 and Bem1. and activated by $\mathrm{Cdc} 24$. Once activated, $S$. cerevisiae $\mathrm{Cdc} 42$ regulates polarized bud growth by regulating the organization of the actin cytoskeleton, the septins, and the exocytic machinery. B) Tea1-Tea4 complex is deposited by microtubules at cell ends, where it is anchored by Mod5. Tea1 binds to Bud6, which binds to For3. Tea4 also binds to the formin For3, which is recruited and activated by Cdc42-Pob1 and Bud6. C) Active Cdc42 distribution in budding and fission yeasts along the cell cycle.

Figure 3. Regulators and targets of Cdc42 in S. cerevisiae and S. pombe.

Figure 4. Schematic representation of $S$. cerevisiae and $S$. pombe MAPK cell integrity pathways. $S$. cerevisiae Rho1 plays a central role in integrating multiple signals from the cell wall sensors and the actin cytoskeleton through GAPs and GEFs to its effectors including Pkc1, which activates the MAPK cell integrity pathway. S. pombe Rho1 and Rho2 activate Pck1 and Pck2. The latter regulates cell wall biosynthetic enzymes and activates the MAPK cell integrity pathway. 


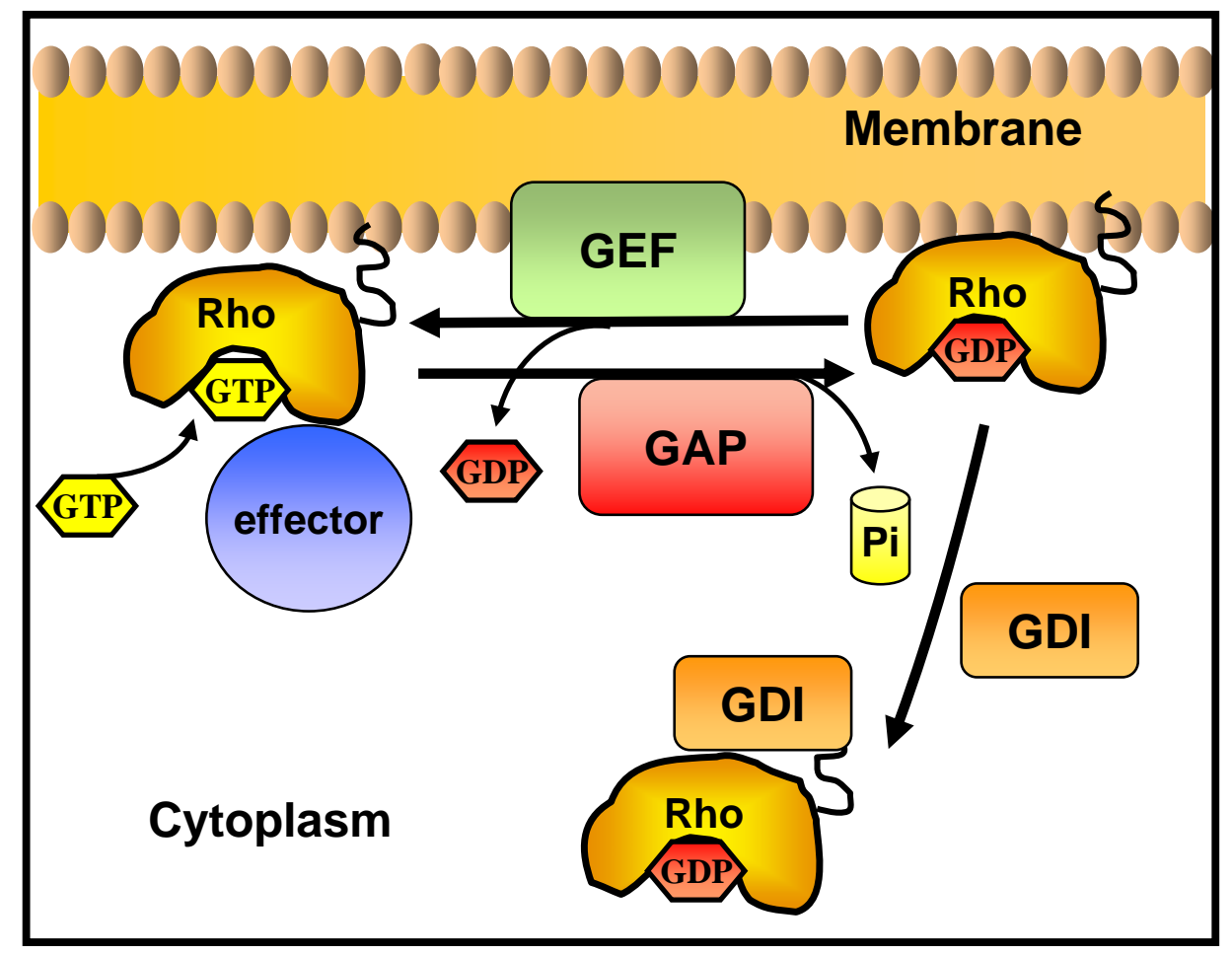

Figura 1 


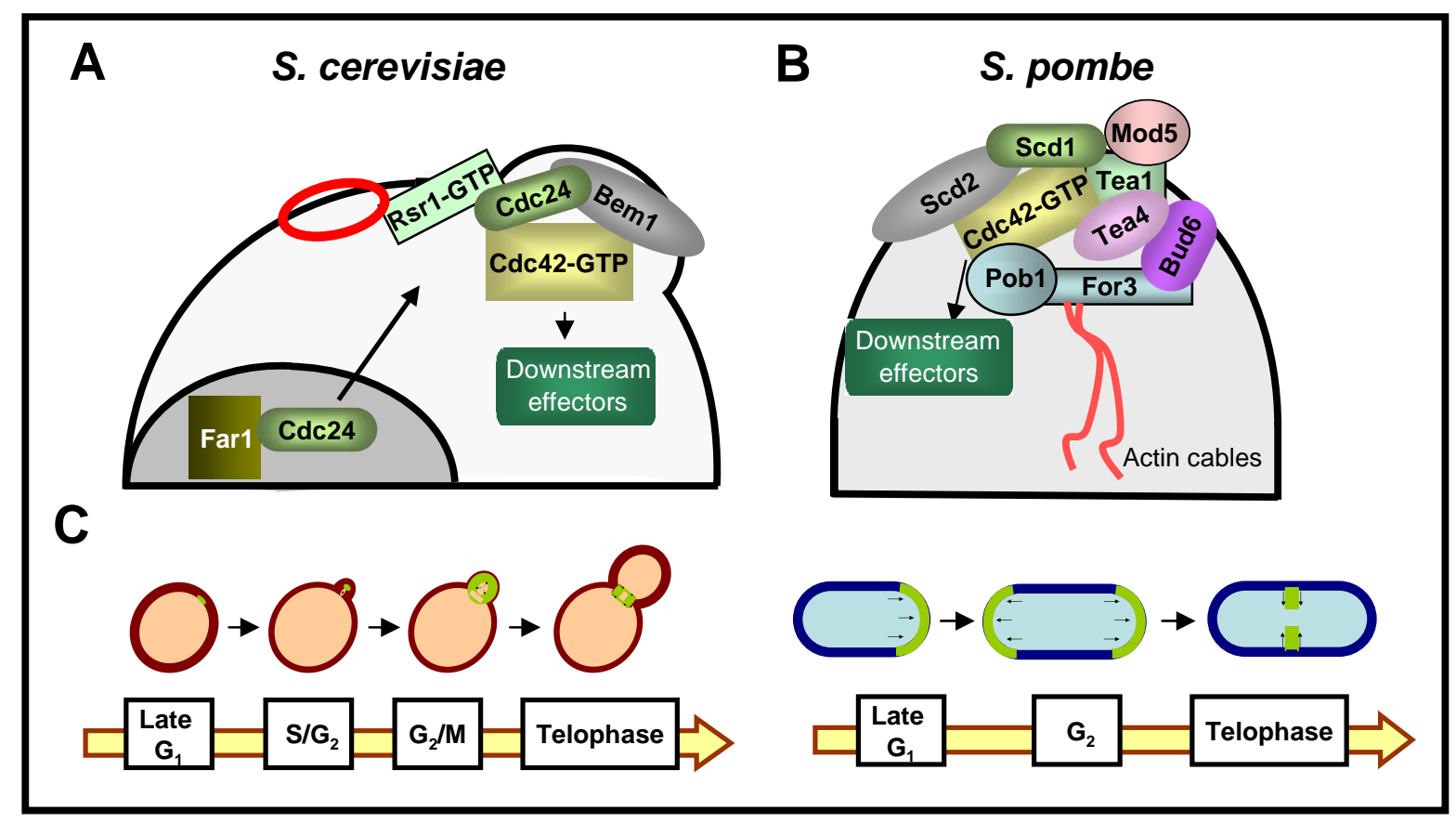

Figura 2 


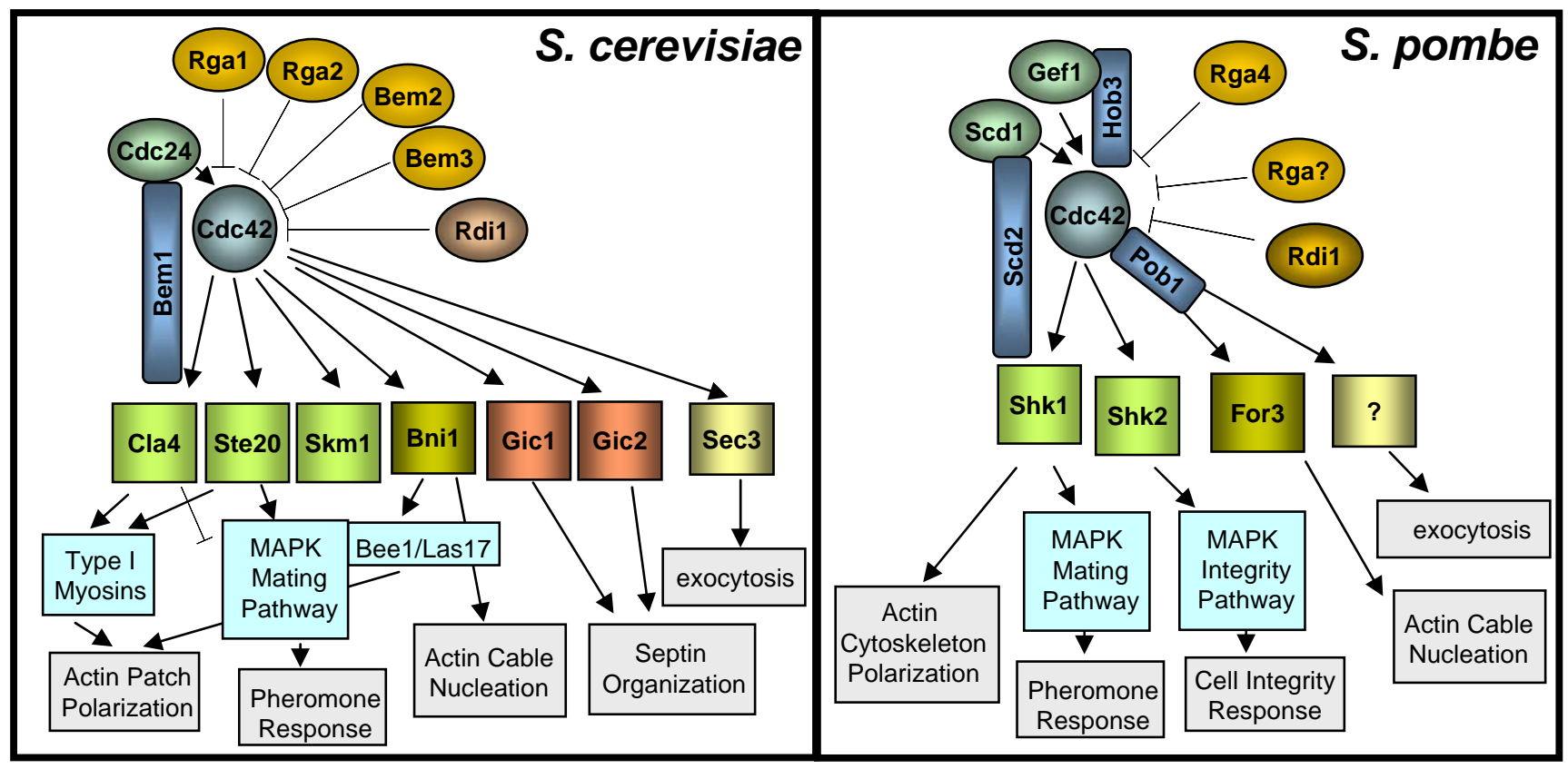

Figura 3 


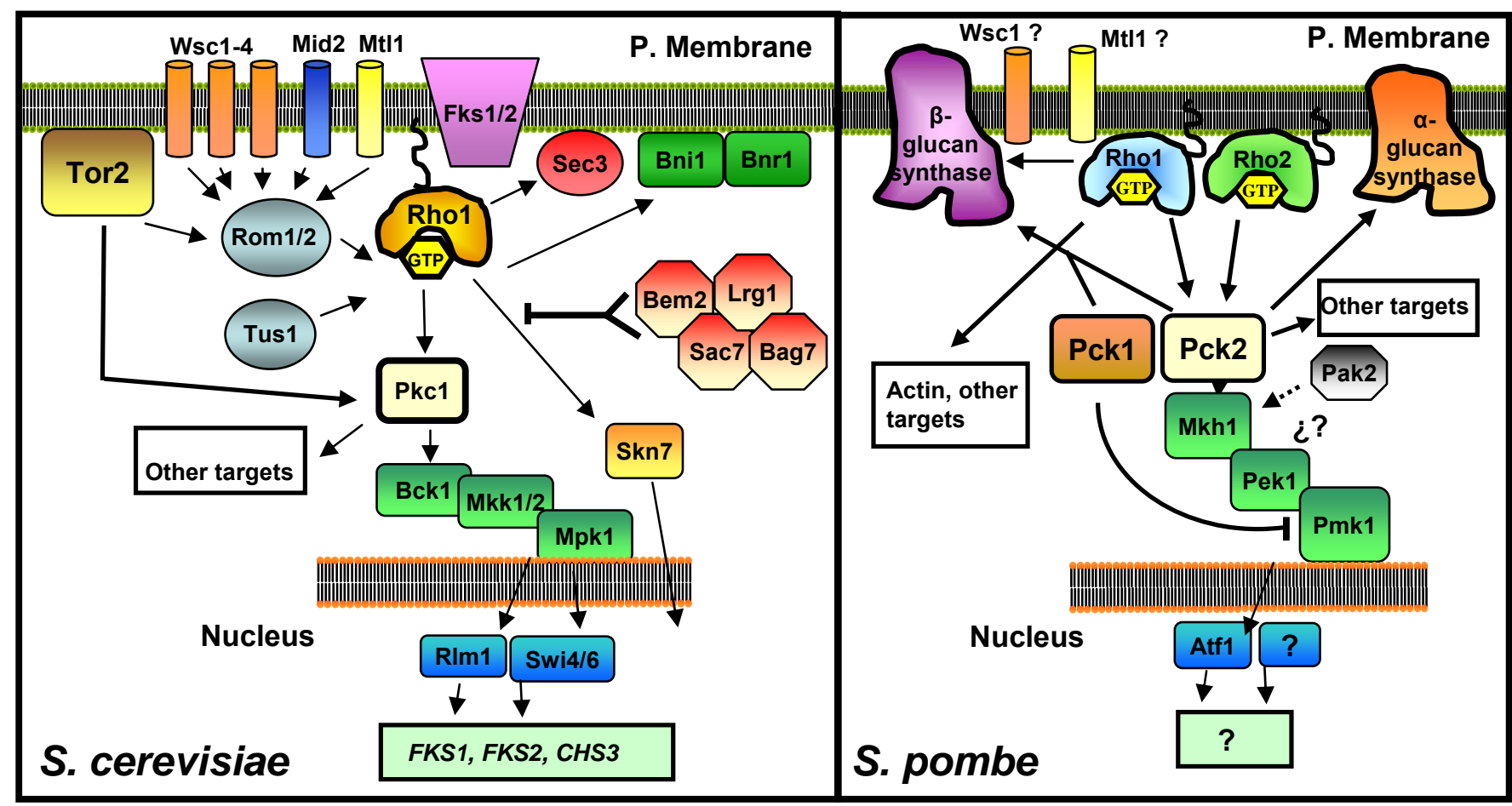

Figura 4 